\title{
The Effect of Multiple Intelligences-based Reading Tasks on EFL Learners' Reading Comprehension
}

\author{
Sima Modirkhamene \\ Department of English Language and Literature, Faculty of Humanities, University of Urmia, Iran \\ Email: s.modir@urmia.ac.ir \\ Mohammad Hossein Bagherian Azhiri \\ Department of English Language and Literature, Faculty of Humanities, University of Urmia, Iran \\ Email: h.azhiry@gmail.com
}

\begin{abstract}
The aim of the present research was to address some fundamental innovative resolutions for EFL learners' encountered impeding dilemmas in reading comprehension. The researchers proceeded to determine the most frequent multiple intelligences (MI) of the EFL learners so as to cater for well-designed tasks to obviate any existing obstacles to ideal reading. Accordingly, by means of a reliable MI profiling questionnaire, the dominant intelligences of EFL learners were highlighted. Moreover, all intended participants were homogenized on the basis of reading proficiency test adopted from First Certificate in English (FCE) whose scores served the purpose of pre-test as well. As a consequence of observed difference between the genders concerning the dominant intelligences, the participants were randomly assigned into distinct control and experimental groups. Furthermore, some evenly selected reading sections from a number of EFL materials, namely, New Inside Out, New Opportunities, and English Online were of primary focus of attention in all groups. As a point of departure, treatment groups were exposed to reading tasks in conformity with already identified dominant intelligences, while the control groups were inclusively conducted under already approached conventional teaching methods of reading in language schools and institutes. The results crystallized the effects of MI-based reading tasks on both EFL male and female learners' reading comprehension. Lastly, findings revealed that EFL female learners emulated their male counterparts' reading comprehension. In sum, the results of such innovative intelligences-based reading task will grant opportunities to discover, value, and enhance the talents of EFL learners in better tackling reading comprehension shortcomings.
\end{abstract}

Index Terms - multiple intelligences, EFL, tasks, reading comprehension

\section{INTRODUCTION}

Diversity in EFL learners and supreme expectations that all students deserve to learn make the tasks of educational teachers daunting. Dealing with individual differences has been one of the biggest issues facing the educational world today. The most crucial contribution that EFL education can make to learners' development is to lead them towards a direction where their inside talents best suit them. Human potentiality as an intriguing factor of success in tandem with educational accomplishments is not to be overlooked at the expense of adherence to the prescribed authoritative rubrics. Tomlinson (2001) subscribes to the view that educationalists must provide the learners with ample opportunities to make sense of their own existing differences and potentials. In support of the preceding claim, Kirby and McDonald (2009) point out that instruction congruous with various scopes of learning motives could extensively establish a sense of belonging, motivation, competence, and enjoyment for the learners. To this end, the significant aim of the researches on individual differences was to foresee which learners would succeed in the learning. Until quite recently, a number of alternatives to traditional approaches of teaching methodology have been suggested, but none of those teaching remedies so far has shown itself in real-world practice (Armstrong, 2009).

A look at the EFL environments underscores the fact that EFL teachers and learners have faced with great many predicaments in their educational life span. To give a birth to EFL learning contexts, very many researchers have resorted to Howard Gardner's theory of intelligences known as multiple intelligences (MI). Unlike traditional approaches to intelligence that were mostly centering on the unitary concept of intelligence, Gardner (1983) disproves a great portion of those obsolete concepts of intelligence and announces that all learners are born with a full range of talents and potentials among which some are naturally robust, and some are weaker in each learner. Garnet (2005) clarifies that such differences do not necessarily make individuals smarter than one another, bur rather assume their being intelligent in distinct ways. Gardner (1983) posits that human brain is designed to process several distinct forms of learning styles referred to as Logical-Mathematical, Musical-Rhythmic, Interpersonal, Intrapersonal, Verbal- 
Linguistic, Bodily-Kinesthetic, and Naturalist. Later, he added the possibility of Existential-Spiritual Intelligence that was not completely defined in his list. By way of illustration, Gardner (2006) argues that "intelligences be assessed in ways that are intelligent-fair and in ways that examine the intelligence directly rather than through the lens of linguistic or logical-mathematical intelligences" (p.55).

A variety of common pitfalls are evident in EFL situations. Learners, at whatever level and from whatever language background and originality have been long deprived of accessing to materials, tasks, catalogues, brochures, booklets, pamphlets and so on in line with maximizing their knowledge of intelligences, self-efficacy, self-worth, and selfexploration in the real life of learning not only in the era of language learning but also in all subject matters. With respect to reading comprehension as one of the major themes of the current study, Armstrong (2003) prioritized MItheory and paved the path towards efficient reading comprehension through the eight gates of intelligences. In fact, he approached reading comprehension beyond the single scope of intelligence endorsed by Howard Gardner (1983) and his advocates.

A closer look at the literature review discloses that a number of MI-tailored studies have recently been carried out in the realm of EFL and many other language related scopes. Some researchers have drawn attention to determining EFL learners' eight types of intelligences and investigating connections between the language skills and these intelligences. To clarify, in a recent study by Hajhashemi et al. (2011), they tended to investigate relationship between EFL learners' MI profiles and their language learning strategies. They worked on 229 EFL students from differing grades and identified their intelligences and language learning strategies by means of the questionnaires. The findings manifested a significant but low correlation between multiple intelligences and language learning strategies. Of all eight types of intelligences, verbal-linguistic, visual-spatial, and logical-mathematical intelligences indicated meaningful correlation with nearly all strategies.

In terms of the merits of MI-based instructions, Baş and Beyhan (2010) ran a research to compare a difference between MI-exposed students with those of traditionally-instructed ones. The fifth-grade learners in experimental group were exposed to multiple intelligences project-based learning activities, while those in control group were instructed merely on the basis of traditionally-designed learning activities. The outcome of the study justified the excellence of MI-suited activities in contrast with the traditional ones. In the same vein, another comparative study has recently been conducted by Stanciu et al. (2011) with the intention of justifying the potential efficiency of MI-based teaching and learning strategies as an improvement upon the traditional methods. The results gave rise to the superiority of MIderived strategies to their traditional counterparts.

With regard to language skills, especially EFL reading as the major issue under investigation, Fahim et al. (2010) concerned with exploring the extent to which the reading sections of TOEFL and IELTS were in line with EFL learners' intelligences. They identified intelligence profiles of 163 (male and female) EFL learners by means of the MI profiling questionnaire. All participants were required of responding to reading sections of TOEFL in 55 minutes and those of IELTS in 60 minutes. The analysis marked the significant correlation between verbal-linguistic and logicalmathematical intelligences and TOEFL reading scores. As with IELTS, verbal-linguistic and visual-spatial intelligences were seen to have significant correlation.

Today, there exists a global consensus upon the fact that language skills are interwoven and should be manipulated in an integrated fashion. Since the present study deals with reading comprehension at the one hand, it is crucial to embark on some studies on other language skills as well. As regards listening, Rezazadeh (2009) investigated the possible relationship between multiple intelligences of EFL learners and their listening proficiency. The participants' intelligence profiles and listening scores achieved by means of the MI questionnaire and TOEFL underwent a correlational analysis. The findings reported visual-spatial and interpersonal intelligences as having the only positive relationship with listening proficiency.

Unlike the previous study, the findings of the research by Naeini and Pandian (2010) ran a counter on the prior study and indicated no significant relationship between intelligences and listening comprehension as a whole or in an isolated fashion. Finally, in regard to EFL writing, Marefat (2007) conducted a research to explore the relationship between learners' MI profiles and their writing products. The results of that study indicated that bodily-kinesthetic and interpersonal intelligences had the highest contribution to EFL learners' writing ability. By the same token, Farzizadeh (2011) contradicted the findings of prior study and found no significant relationship between EFL students' writing ability and their eight types of intelligences. A closer look at the literature review makes it evident that no study has been vigorously carried out to deeply inject the use of MI-based reading tasks into the process of reading comprehension among EFL learners. Consequently, much work still remains to be done on this subject.

\section{METHOD}

\section{A. Participants}

A total number of 70 participants including 40 male and 30 female Iranian intermediate EFL learners within the age range of 16-23 participated in the present study. An adopted reading proficiency test from FCE was used with the purpose of homogenizing the participants in terms of reading proficiency. Since both genders showed varying dominant intelligences, especially with respect to the logical-mathematical and the verbal-linguistic intelligences, they were assigned into separate groups (20 males and 15 females in each of the two control and two experimental groups). 


\section{B. Instrumentation}

Firstly, to practically set the ground for the sake of putting into practice the already mentioned theoretical aspects of the current study, at the macro level, a highly valid and reliable MI-based profiling questionnaire prepared by Armstrong (1994) was utilized in the study in order for accentuating the most highly frequent intelligences among the participants. Secondly, a reading proficiency test adopted from FCE was used serving the purposes of both homogenizing the participants and pretest at the outset of the study. Finally, some reading sections of New Inside Out by Kay and Jones (2000), New Opportunities by Harris et al. (2006), English online, Animal Collage by Lahav et al. (2005), and English Online, Music Mania by Nurick et al. (2004) were of primary focus of attention in all intended groups.

\section{Procedure}

A pilot study was conducted with intermediate EFL learners $(\mathrm{N}=30)$ and the reliability analysis showed that the Cronbach's alpha reliability coefficient was 0.73 , indicating that the instrument could be considered as the reliable tool.

For any sort of comment to be effective, both control and experimental groups were alike in terms of setting, materials, and educational facilities except for the treatment that the experimental groups were exposed to. Following these steps, the major scenario of the study was commenced. Such a course took long for two months including 24 sessions (three 90-minute sessions every week). Prior to anything stepping forward, based on all participants' profiling questionnaires, the most highly frequent intelligences among males were identified as being interpersonal, logicalmathematical, naturalist, musical, and intelligences. Females were seen to have interpersonal, musical, naturalist, and linguistic intelligences as the dominant proclivities. Unlike females who highlighted verbal/linguistic intelligence as one of the most frequent intelligence type, males were seen not to show this profile as one of their most highly frequent proclivities.

All intended sessions in the established groups (control/experimental) were dedicated to handling with evenlyselected reading passages from those previously introduced EFL books. As regards control groups, they all received sort of placebo with respect to reading comprehension. The researchers resorted to already-existing instructional fashions in teaching reading. They mainly made use of pre-reading, reading, and post-reading strategies including warm-ups, scanning, skimming, looking for main ideas, and responding to true-false and comprehension questions inserted to the bottom of each passage.

In the experimental groups also all above mentioned materials were used in line with the most frequent intelligences among males and females. As regards interpersonal intelligence, participants were reinforced to make discussion teams while and after reading. Also, they were directed towards pair and group reading in a highly friendly situation. Another important task for them was the implication of the peer interviews on the basis of reading tasks being used. In groups, participants were stimulated to experience peer teaching in a highly cooperative fashion. The instructors recommended them to share and peer edit what they read to raise their own social awareness. What motivated the participants was the act of filming, voice recording their peer or group works while dealing with reading tasks that was later shown on the wall screen through the use of video projector.

With respect to the verbal-linguistic intelligence as one of the dominant intelligences merely in females' experimental group, the participants approached reading materials by calling on the tasks of retelling, summarizing, criticizing, reading aloud, listening, discussing, writing notes, lecturing, debating, and generalizing what they were reading.

In terms of the musical intelligence, the participants were encouraged to eagerly identify any favorite-sounding words and highlight sounds of particularly interesting words or expressions. Dealing with certain pre-selected rhythmic reading tasks, they were required of reading the text rhythmically out loud similar to poem-reciting or English-singing fashions. Sometimes, they were deeply reinforced to rhythmically chant out the given reading task as a group. Furthermore, while reading the material, the instructors recorded and played their voices several times by means of the high-tech voice recorder. In practice, while silently reading the texts, relaxing pieces of soft speechless music including Classics, Mozart, and several other peaceful tracks of music were taken into greater practice. Besides, some parts of musical-therapy collections adapted from www.Roozberooz.com were being played in background simultaneously.

Interestingly enough, to put into effect naturalist intelligence, a number of texts with the theme of nature, adapted from those already introduced EFL books, played great roles in these classes In addition, naturalist imagery later was appreciated as the highly enjoyable task, requiring the participants to go beyond the current learning situation, to experience the scenes, and to feel, smell, touch, fancy, and dream about things happening in the text as though they had been in the real-world naturalist environment. As the highly welcomed task, a variety of natural sound effects, environmental, natural sounds such as rain-falling, wind-blowing, thunder-storming, as well as sounds of jungles, rainforests, waterfalls, volcanoes, tornadoes, hurricanes, showers, oceans and etc. adapted from www.soundeffectpack.com were being played in background. To the surprise of many, for two sessions, participants were invited to participate in outdoor classes. While conducting a class indoors, the instructors purposefully attached some task-related natural posters and pictures on the walls.

With respect to the logical-mathematical intelligence, participants were led to accentuate patterns like problemsolving and cause-effect ones. Deeply involved in the reading task itself, participants were attempting to predict and 
infer about what the unfamiliar words and ambiguous sentences meant. They also got engaged in recognizing the thesis statements, topic sentences, major, minor supports, references, and their referents within the given task. While reading, they went on the process of hypothetical-testing strategies by resorting to the questions they asked while reading to resolve any existing predicaments. Identifying the kind of reading material (fiction, non-fiction, science writing, definition, description, novel, story, poem, play, letter, and etc.) was another task carried out by the participants. Moreover, participants were directed towards deciding on the logic, coherence, titles, subtitles, key events, contradictions, and redundancies in the text. The participants were also helpfully involved in computing the readability of a text by applying a simple readability formula to the text they were reading. The reason was that such a task could help EFL readers step into the world of reading materials more interestingly.

Accordingly, the study scrutinized the following main research questions:

1) What are the most frequent types of intelligences among intermediate EFL learners?

2) Do MI-based reading tasks have any effect on intermediate EFL male learners' reading comprehension?

3) Do MI-based reading tasks have any effect on intermediate EFL female learners' reading comprehension?

4) Do MI-based reading tasks have different effects on intermediate EFL male and female learners' reading comprehension?

\section{RESUlTS AND ANALYSIS}

\section{A. Research Question 1}

Prior to the main findings of the current study, the initial inquiry based on the received data from MI profiling questionnaire revealed that interpersonal, logical-mathematical, naturalist, and musical intelligences were of greater dominance among EFL male learners. Female learners, on the other hand, demonstrated interpersonal, musical, naturalist, and verbal-linguistic intelligences as their most highly frequent intelligences. As a point of departure, these results disapproved the equality of both genders with respect to dominant intelligences.

\section{B. Data Analysis for Research Question 2}

In order to investigate the main research questions of this study, a mixed between-within subjects' analysis of variance was implemented to see the consequences of the presence and absence of MI-based treatment in experimental and control groups. This was manipulated to see if there were main effects for the subject groups (control vs. experimental) and for the time. Besides, it was utilized to see the main effects for their interaction. In other words, it was applied to see if the change in reading comprehension over the time was different for the two groups.

TABLE 1

READING SCORES OF MALES IN CONTROL AND EXPERIMENTAL GROUPS

\begin{tabular}{lllll}
\hline & Group & Mean & Std. Deviation & N \\
\hline \multirow{3}{*}{ Pre-Test } & Experimental & 12.1000 & 1.20961 & 20 \\
& Control & 11.9000 & 1.25237 & 20 \\
& Total & 12.0000 & 1.21950 & 40 \\
\hline \multirow{3}{*}{ Post-Test } & Experimental & 14.5000 & 1.10024 & 20 \\
& Control & 12.6500 & 1.34849 & 20 \\
& Total & 13.5750 & 1.53402 & 40 \\
\hline
\end{tabular}

According to Table 1, the male participants' mean score of pretest in experimental group is 12.10 and in control group it equals 11.90. With respect to post-test scores, the mean score of males in control group is seen to be 12.65 , whereas in experimental group this value rise up to 14.50 . However, such differences between mean scores within each group need to be statistically justified.

TABLE 2

MULTIVARIATE TEST (MALE GROUPS)

\begin{tabular}{|c|c|c|c|c|c|c|c|}
\hline Effect & & Value & $\mathrm{F}$ & Hypothesis df & Error df & Sig. & Partial Eta Squared \\
\hline Time & Wilks' Lambda & .258 & 109.133(a) & 1.000 & 38.000 & .000 & .742 \\
\hline Time* Group & Wilks' Lambda & .559 & $29.944(a)$ & 1.000 & 38.000 & .000 & .441 \\
\hline
\end{tabular}

Prior to investigating the main effects of MI-based reading tasks in control and experimental groups, there is a necessity to check the interaction effect in order to see if there is a change in reading comprehension scores of both control and experimental groups over the time. This is statistically highlighted in the second row in the Multivariate Tests, Table 2 (Time*Group). The value of Wilk's Lambada as the most commonly reported statistics in this study yields the Sig. level of 0.000 which is less than the alpha level of 0.05 . By looking at the main effects for each of the independent variables (Time and Treatment), the value for Wilk's Lambada for time is calculated as 0.258 with a probability value of 0.000 , so there is a statistically significant effect for time. This shows that there is a change in reading comprehension scores of participants from test-time 1 (pre-test) to test-time 2 (post-test) in both control and experimental groups. 
Table 3 illustrates the main effect of MI-based reading tasks between males' control and experimental groups. The information reveals that there is a significant difference between the reading comprehension of participants in control and experimental groups at the end of the treatment period. Such statistical values $(F=8.15$, Sig. $=0.007)$ manifest the fact that the use of MI-based reading tasks highly affect the reading comprehension of male participants in experimental group. More importantly, although the reading comprehension scores of participants increased in control and experimental groups, the information in Table 3 discloses the reality that this increase in experimental groups is statistically higher than that of control group among male participants. Thus, such a difference is due to the implementation of MI-based reading tasks among males in experimental group.

TABLE 3

TESTS OF BETWEEN SUBJECTS EFFECTS (MALES)

\begin{tabular}{lllllll}
\hline Source & Type III Sum of Squares & df & Mean Square & F & Sig. & Partial Eta Squared \\
\hline Intercept & 13081.612 & 1 & 13081.612 & 5078.940 & .000 & .993 \\
Group & 21.012 & 1 & 21.012 & 8.158 & .007 & .177 \\
Error & 97.875 & 38 & 2.576 & & & \\
\hline
\end{tabular}

All the above mentioned findings are magnified in the Figure 1 for the sake of clarity. According to this figure, the homogenized male participants at the time of post-test show progress in terms of reading comprehension in both groups, but the direction of the two lines makes it clear that participants in experimental groups excel those in control groups. Consequently, the first research question can be firmly answered claiming that the MI-based reading tasks significantly affect EFL male learners' reading comprehension.

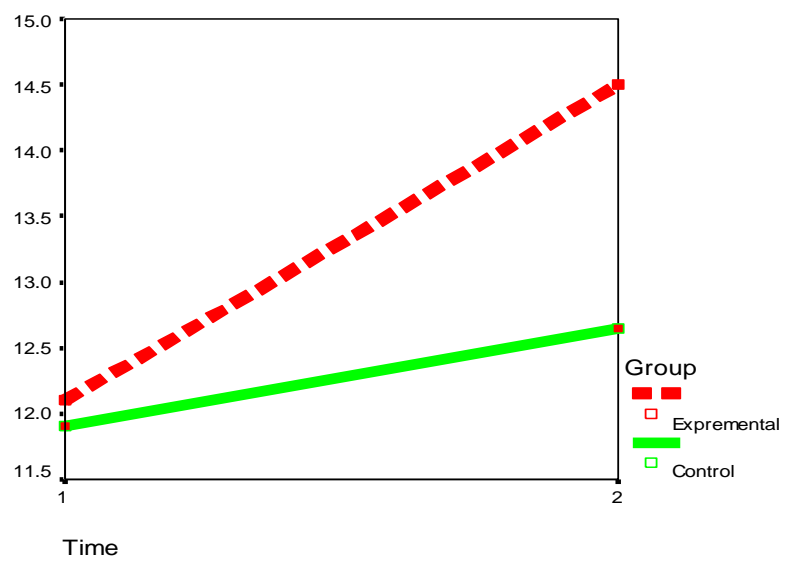

Figure 1: Comparison of Males' Reading Scores in Both Groups

C. Data Analysis for Research question 3

Do MI-based reading tasks have any effect on EFL female learners' reading comprehension?

TABLE 4

READING SCORES OF FEMALES IN CONTROL AND EXPERIMENTAL GROUPS

\begin{tabular}{lllll}
\hline & Group & Mean & Std. Deviation & $\mathrm{N}$ \\
\hline Pre-Test & Experimental & 12.8667 & 1.24595 & 15 \\
& Control & 13.1333 & 1.24595 & 15 \\
& Total & 13.0000 & 1.23176 & 30 \\
\hline Post-Test & experimental & 16.5333 & 1.18723 & 15 \\
& control & 13.8000 & 1.26491 & 15 \\
& Total & 15.1667 & 1.83985 & 30 \\
\hline
\end{tabular}

Table 4 provides information about the mean and standard deviation for the groups. As it is displayed, the mean value of the pretest in the experimental group equals 12.86 and in the control group is calculated as 13.13. On the other hand, the mean value of post-test in the experimental group is 16.53 and in the control group this value equals 13.80 .

TABLE 5

MULTIVARIATE TESTS (FEMALE GROUPS)

\begin{tabular}{llllllll}
\hline Effect & & Value & F & Hypothesis df & Error df & Sig. & Partial Eta Squared \\
\hline Time & Wilks' Lambda & .094 & $268.864(\mathrm{a})$ & 1.000 & 28.000 & .000 & .906 \\
Time * Group & Wilks' Lambda & .178 & $128.864(\mathrm{a})$ & 1.000 & 28.000 & .000 & .822 \\
\hline
\end{tabular}

By looking at the information presented in Table 5, it becomes evident that the main effect for time from test-time 1 to test-time 2 is statistically significant with the Sig. value of 0.000 which is less than 0.05 . That is to say, the reading 
comprehension of the female participants changed across the time. Moreover, the interaction effect of time and group which is significant with the Sig. value of 0.000 manifests the fact that there was not the same change in female participants' reading comprehension over time for the experimental versus control groups. Moving to the statistical information displayed in Table 6, it becomes clear that the Sig. value for group is 0.008 which is less than 0.05 , so the main effect for group is seen to be significant. This means that the use of MI-based reading tasks among female participants affected their reading comprehension. Thus, the third research question is answered.

TABLE 6

TESTS OF BETWEEN-SUBJECTS EFFECTS (FEMALES)

\begin{tabular}{lllllll}
\hline Source & Type III Sum of Squares & df & Mean Square & F & Sig. & Partial Eta Squared \\
\hline Intercept & 11900.417 & 1 & 11900.417 & 4257.389 & .000 & .993 \\
Group & 22.817 & 1 & 22.817 & 8.163 & .008 & .226 \\
Error & 78.267 & 28 & 2.795 & & & \\
\hline
\end{tabular}

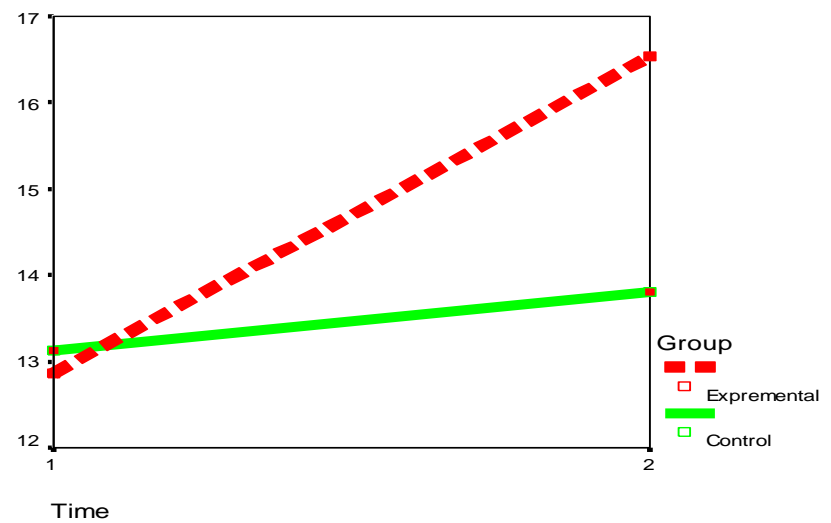

Figure 2: Comparison of Females’ Reading Scores in Both Groups

As it is illustrated in Figure 2, female participants in both control and experimental groups show progress in their reading comprehension across time; however, the point is that this increase in the experimental group was evidently seen to be statistically greater than that of control group which provided significant results for the effect of MI-based reading tasks in this group.

\section{Data Analysis for Research Question 4}

As regards the last research question of the current investigation that is about investigating any difference between male and female participants' reading comprehension at test-time 2 after being exposed to MI-based treatment in both experimental groups, a two-way ANCOVA is utilized by assuming two independent categorical variables with two levels (Group and Gender), one dependent continuous variable (Post-Test), and one continuous covariate (Pre-Test).

The information presented in Table 7 demonstrates male and female participants' post-test results in both control and experimental groups. As it can be viewed, the mean score of females in experimental group is 16.53, while that of males in experimental group equals 14.50 , yet such a tabulated difference needs to be statistically justified.

TABLE 7

DESCRIPTIVE STATISTICS (POST-TEST)

\begin{tabular}{lllll}
\hline Gender & Group & Mean & Std. Deviation & $\mathrm{N}$ \\
\hline Male & Experimental & 14.5000 & 1.10024 & 20 \\
& Control & 12.6500 & 1.34849 & 20 \\
& Total & 13.5750 & 1.53402 & 40 \\
\hline Female & Experimental & 16.5333 & 1.18723 & 15 \\
& Control & 13.8000 & 1.26491 & 15 \\
& Total & 15.1667 & 1.83985 & 30 \\
\hline Total & experimental & 15.3714 & 1.51630 & 35 \\
& control & 13.1429 & 1.41718 & 35 \\
& Total & 14.2571 & 1.83907 & 70 \\
\hline
\end{tabular}

TABLE 8

TESTS OF BETWEEN-SUBJECTS EFFECTS (MALES AND FEMALES)

\begin{tabular}{lllllll}
\hline Source & Type III Sum of Squares & df & Mean Square & F & Sig. & Partial Eta Squared \\
\hline Gender & 10.391 & 1 & 10.391 & 15.750 & .000 & .195 \\
Group & 91.987 & 1 & 91.987 & 139.428 & .000 & .682 \\
Gender * Group & 6.458 & 1 & 6.458 & 9.788 & .003 & .131 \\
\hline
\end{tabular}


In what followed, the tests of between-subjects effects are illustrated in Table 8. In this table, of most interest is the interaction effect. Statistically speaking, if this interaction (Gender*Group) is significant, then the other two main effects are not that much important. This is because of the fact that the effect of one independent variable is dependent on the level of other independent variable. In THIS study, the Sig. value for this equals 0.003 which is less than 0.05 ; therefore, the interaction effect is seen to be significant. This suggests that the implementation of MI-based reading tasks is of different benefits to EFL male and female learners.

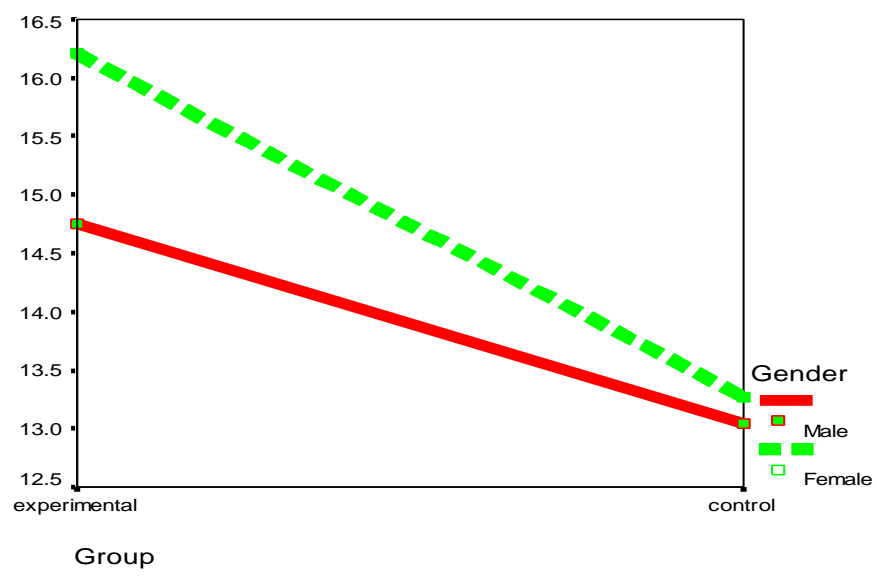

Figure 3: Comparison of Groups across Genders

Lastly, the above illustrated plot of an estimated marginal means of post-test (Figure 3) provides us with the adjusted means on the dependent variable (reading comprehension at test-time 2) for each of the groups among males and females. The term 'adjusted' calls on the fact that the effect of covariate (Pre-Test value) has been statistically removed. It is now clear from this plot that there is an interaction between the two independent variables (group and gender). This obviously suggests that males and females appear to be benefiting differently from the MI-based treatment. A closer look at the plot makes it clear that both male and female experimental groups have shown greater advancement in their reading comprehension in contrast with control groups; however, females have improved more than their male counterparts. At this point, the final research question can be answered justifying that there is a significant difference between EFL male and female learners' reading comprehension after being exposed to MI-based reading tasks.

\section{CONCLUSIONS}

In a nutshell, the present study concentrated on the implementation of the MI-based reading tasks to see their potential effects on EFL learners' reading comprehension. The findings made it clear that EFL male and female learners do not entirely possess the same kinds of intelligences as their dominant proclivities. The results justify that EFL male learners manifested interpersonal, logical-mathematical, naturalist, and musical intelligence as to be their dominant intelligences, while females accentuated interpersonal, musical, naturalist, and verbal-linguistic as their dominant intelligences. Thus, the goal of the current research was to prepare EFL students to succeed in the real world reading comprehension, not just to excel in EFL schools and institutes. They need to perform well in EFL educational contexts, but that is just the beginning. Success is measured in various ways in EFL environments and in life. Real success, though, comes to ground with a sense of happiness and satisfaction. It is by now clear that for EFL learners to be successful, they need to be capable of finding a context in which their potential strengths come to the fore and their weaknesses are diminished. The ultimate goal in all learning situations should be to accentuate the merit of the intelligences and to teach and reinforce their development in every EFL learner.

A look at the literature review reveals that the findings of this study run a counter on the findings of the study by Saricaoğlu and Arikan (2009) who showed logical-mathematical intelligence as the only contributing factor in language learning. Moreover, the dominance of the intelligences in the present study is contrary to those of Saricaoğlu and Arikan that statistically marked verbal-linguistic and musical intelligences as the least dominant ones. The reason for this can be due to different learning environment factors and age or different study level. It can be assumed that EFL learners' multiple intelligences are gradually rolling upon the educational continuum as they are growing up. The findings of the study also oppose those of achieved by Hashemi (2007) who showed bodily-kinesthetic intelligence as the strongest and naturalist as the weakest type. Also Hashemi had found verbal-linguistic as the only predictor of learners' reading ability, while the present study explored the positive effects of Interpersonal, musical, naturalist, logical-mathematical, and linguistic-based tasks on EFL learners' reading performance. The positive pedagogical claims of the current article is a guarantee for the other positive trends of MI-based approaches to EFL education that have recently been shown by Stanciu et al. (2011); Baş and Beyhan (2010); and Sólmundardóttir (2008) who all investigated and proved the positive impact of MI-based instructions and activities in the process of learning. The 
findings are also partly in line with those of Fahim et al. (2010) who found a significant correlation between verballinguistic, logical-mathematical, and reading scores of TOEFL exam. As it was shown, kinesthetic intelligence in the current study received a lower rank that again supports the existence of negative correlation found by Fahim et al. For any sort of comment to be effective, it should be notified that when dealing with EFL learners' listening, reading, writing, speaking skills, and many other language learning aspects; Howard Gardner's' eight types of intelligences might or might not have meaningful relationships with or effects on EFL learners performance due to a variety of existing educational, curricular, environmental, individual, and many other factors. Consequently, findings of any MIrelated projects or studies require a great deal of caution when generalizing to other EFL contexts.

Curriculum developers bear the greater burden of establishing any desirable and efficient norms and standards of EFL learning in a variety of educational fields. A long-term programming as well as the required budget need to be officially ratified in advance of educating the learners of the community. A great deal of EFL books taught in EFL situations are entirely planned, designed, and published by some well-known publications in the world having specific rationale behind themselves. A closer look at such materials that approach all language skills from a variety of perspectives and angles would make it clear that the term 'intelligence' is not an overt point of departure in constructing and sequencing the materials.

In order for the theory of MI to be potently implemented, all constituencies in the schools, EFL institutes, and other educational environments should be in pursuit of understanding and embracing this model. In a deeper sense, it means that not only the teachers, administrators, curriculum developers, and EFL practitioners but also students, parents themselves need some basic knowledge of MI theory for the implication to be as illuminating as possible. To share this information with all members of the educational contexts is an essential and critical phase in the process of appreciating multiple intelligences in every learning environment especially in Iranian EFL context.

Many EFL teachers are evidently unaware of the benefits of such a contributing asset in the process of teaching. The more crucial consideration for teachers is to make sure that often during the educational period; they have opportunities for those learners who are robust in some intelligence other than the linguistic and logical-mathematical to be greatly successful. Such a genuine teaching fashion would be highly rewarding for the students themselves because they will deeply witness and explore a new love of learning in their EFL life span.

\section{REFERENCES}

[1] Armstrong, T. (1994). Multiple intelligences in the classroom. USA: Association for Supervision and Curriculum development.

[2] Armstrong, T. (2003). The multiple intelligences of reading and writing. Making the words come alive. VA, USA: Association for Supervision and Curriculum Development.

[3] Armstrong, T. (2009). Multiple intelligences in the classroom ( $3^{\text {rd }}$ ed.). USA: Association for Supervision and Curriculum Development.

[4] Baş, G. \& Beyhan, Ö. (2010). Effects of multiple intelligences supported project-based learning on students' achievement levels and attitudes towards English lessons. International Electronic Journal of Elementary Education, Vol (3), pp 365-386.

[5] Fahim, M., Bagherkazemi, M., \& Alemi, M. (2010). The relationship between test takers' multiple intelligences and their performance on the reading sections of TOEFL and IELTS. Broad research in Artificial Intelligence and Neuroscience, Vol (1), pp 1-14.

[6] Farzizadeh, B. (2011). The relationship between Iranian EFL learners' emotional intelligence, multiple intelligences and their writing abilities. MA dissertation, Urmia University, Iran.

[7] Gardner, H. (1983). Frames of mind. The theory of multiple intelligences. USA: Basic Books.

[8] Gardner, H. (2006). The Development and Education of the Mind. The selected works of Howard Gardner. USA: Routledge.

[9] Garnett, S. (2005). Using Brainpower in the Classroom. Five steps to accelerate learning. New York: Routledge Taylor \& Francis Group.

[10] Hajhashemi, K., Parastesh Ghmbavani, F., \& Yazdi Amirkhiz, S. Y. (2011). The relationship between Iranian EFL high school students' multiple intelligences scores and their use of learning strategies. English Language Teaching, Vol (4), pp 214-222.

[11] Harris, M., Mower, D., \& Sikorzyńska, A. (2006). New opportunities. Education for life. Spain: Longman Pearson Education Limited.

[12] Hashemi, A. (2007). The relationship between multiple intelligences and reading comprehension. Andishe Va Raftar, Vol (2), 100-110.

[13] Kay, S. \& Jones, V. (2000). New inside out. Oxford: Macmillan Publishers Limited.

[14] Kirby, E. \& McDonald, J. (2009). Engage Every Student. Motivation Tools for teachers and Parents. USA: Search Institute.

[15] Lahav, D., Nurick, L. M., Ruttenberg, A., \& Sommer, B. (2005). English Online. Animal Collage. Israel: Centre for Educational Technology.

[16] Marefat, F. (2007). Multiple Intelligences: Voices from EFL Writing Class. Pazhuheshe Zabahaye Khareji, 32, pp 145-162.

[17] Naeini, M., \& Pandian, A. (2010). On the Possible relationships between Multiple Intelligences, Listening Proficiency and Motivational Orientation among Iranian TEFL University Students. The Iranian EFL Journal, Vol (6), pp 75-95.

[18] Nurick, L. M., Spector-Cohen, E., Adin, A., Lahav, D., \& Sommer, B. (2004). English Online. Music Mania. Israel: Centre for Educational Technology.

[19] Rezazadeh, E. (2009). The possible relationship between eight intelligence types and listening comprehension of Iranian EFL learners. MA dissertation, University of Urmia, Iran.

[20] Saricaoğlu, A. \& Arikan, A. (2009). A Study of Multiple Intelligences, Foreign Language Success and Some Selected Variables. Journal of Theory and Practice in Education, Vol (5), pp 110-122. 
[21] Sólmundardóttir, A. S. (2008). The multiple intelligence theory in English language teaching. Theme-based lesson plans on Hollowean. Retrieved April 24, 2011, from http://skemman.is/stream/get/1946/1485/4473/1/adal_adal.pdf

[22] Stanciu, d., Orban, I., \& Bocoş, M. (2011). Applying the multiple intelligences theory into pedagogical practice. Lessons from the Romanian primary education system. Procedia Social and Behavioral Sciences, Vol (11), pp 92-96.

[23] Tomlinson, C. A. (2001). How to Differentiate Instruction in Mixed-Ability Classrooms (2 ${ }^{\text {nd }}$ ed.). USA: Association for Supervision and Curriculum Development.

Sima Modirkhamene, born in Iran, holds a PhD in TEFL/TESOL from the University of Surrey, UK. Since her return to Iran in September 2006, she has been lecturing at undergraduate and postgraduate levels and researching in Urmia University, Iran. Her main research interests include: bilingualism, first and second language acquisition, cross-linguistic transfer, and multiple intelligences in relation to language learning. She has served as the Deputy Head of the Foreign Languages Center of Urmia University since 2008 .

Mohammad Hossein Bagherian Azhiri, from Iran, is an EFL instructor finalizing his MA course in TEFL in Urmia State University, Urmia, Iran holding a BA in the same field from Tabriz Islamic Azad University, Tabriz, Iran. He is interested in language teaching and learning, and is looking forward to conducting pioneering researches in psycholinguistics, applied linguistics, SLA, multiple intelligences, emotional intelligences, and discourse analyses. 